\title{
Dermatitis eczematosa alérgica por contacto al níquel. Presentación de un caso
}

\author{
Yuriet Alexandra Tibaduiza-Mogollóna
}

\begin{abstract}
Resumen: Las reacciones alérgicas al níquel son frecuentes, dados los amplios usos y cualidades que ha demostrado este elemento en la producción industrial; la dermatitis por níquel, aunque afectaba de manera predominante a las mujeres, ha incrementado en los hombres por el uso de accesorios, joyería y bisutería.

Las manifestaciones por sensibilización sistémica se conocen como "sarna de níquel" y recuerdan las lesiones de la escabiosis; esta forma clínica ha sido poco notificada en la literatura médica. En este artículo se presenta a una paciente con cuadro clínico típico de dermatitis eczematosa alérgica por contacto al níquel a nivel infra umbilical, con lesiones tales como eritema, edema, vesículas, pápulas, costras hemáticas, liquenificación por fricción crónica y fisuras. La paciente había presentado un año antes "Sarna de níquel".

Palabras clave: dermatitis; eccema; eritema

Fecha de recepción: 8 de febrero de 2018 Fecha de aprobación: 19 de octubre de 2018

Cómo citar: Tibaduiza Mogollon YA. Dermatitis eczematosa alérgica por contacto al níquel. Presentación de un caso. Revista Med. 27(1):85-89. Disponible en: https://revistas.unimilitar.edu.co/index.php/rmed/article/view/3166
\end{abstract}

a Médica cirujana, Unidad Médica, Tunja, Colombia.

Correo electrónico: alexandratibaduiza@hotmail.com 


\title{
Allergic Eczema Due to Nickel Contact. Case Report
}

\begin{abstract}
Allergic reactions to nickel are frequent, given the wide uses and properties that this element has shown in industrial production. Although nickel dermatitis has predominantly affected women, it has increased in men due to the use of accessories and jewelry. Systemic sensitization manifestations are known as "nickel scabies" and resemble scabiosis lesions; this clinical form has been poorly reported by medical literature. This article presents a patient with a typical clinical picture of allergic eczema due to nickel contact at the infra-umbilical level, with lesions such as erythema, edema, blisters, papules, blood scabs, chronic friction lichenification, and fissures. The patient had had "nickel scabies" a year ago.
\end{abstract}

Keywords: Dermatitis; eczema; erythema

\section{Dermatite eczematosa alérgica por contato com o níquel. Apresentação de um caso}

Resumo: As reações alérgicas ao níquel são frequentes, tendo em vista os amplos usos e qualidades que esse elemento demonstra na produção industrial. A dermatite por níquel, embora afetasse de maneira predominante as mulheres, tem aumentado nos homens pelo uso de acessórios, joias e bijuterias. As manifestações por sensibilização sistêmica são conhecidas como "sarna de níquel" e lembram as lesões da escabiose. Essa forma clínica tem sido pouco documentada na literatura médica. Neste artigo, é apresentada uma paciente com quadro clínico típico de dermatite eczematosa alérgica por contato com o níquel em nível infraumbilical, com lesões como eritema, edema, vesículas, pápulas, crostas hemáticas, liquenificação por fricção crônica e fissuras. A paciente tinha apresentado um ano antes a "sarna de níquel".

Palavras-chave: dermatite; eczema; eritema 


\section{Introducción}

La sensibilidad al níquel aqueja aproximadamente al $10 \%$ de las mujeres y al $1 \%$ de los hombres (1). En algún momento se consideró su incidencia predominantemente de origen ocupacional; en la actualidad al incremento de su uso en aleaciones de joyería y bisutería, ya que el contacto a este metal podría afectar a una gran parte de la población, sin estar aunada a factores laborales. A pesar de que la concentración de níquel en los utensilios es regulada y que desde 1989 el Gobierno danés estableció el máximo de liberación semanal de níquel de 0,5 $\mu \mathrm{g} / \mathrm{cm} 2$ para los objetos que estuvieran en contacto con la piel, se sabe que cantidades menores a $5 \mathrm{mg} / \mathrm{cm} 2$ por semana pueden causar dermatitis en pacientes con sensibilización previa (2); esto incrementa con la exposición crónica al metal bajo la potencialización de la penetración en piel con humedad, sudor y detergente (3).

\section{Caso clínico}

Se trata de una paciente femenina de 21 años de edad, proveniente de Sogamoso (Boyacá), sin antecedentes clínicos de importancia. La paciente se presenta a la consulta por prurito a nivel infra umbilical, y refiere que previamente utilizó crema a base de úrea y antihistamínico (Loratadina) para control de cuadro clínico que presenta desde los 14 años de edad, con respuesta aceptable en ese entonces. Cuando consulta, refiere sentir prurito intenso en todo el cuerpo, lo cual le impedía continuar sus actividades cotidianas; asimismo, que desde que iniciaron los síntomas la constante ha sido la intermitencia de resolución y reaparición de las lesiones muchas veces. Hasta el momento no tiene claridad de cuál es la causa de su condición, pero comenta que en el 2016, presentó lesiones similares a la que muestra en el examen físico, aunque menciona que se ubicaban en diferentes zonas, como piel en contacto con los broches del sostén, en las flexuras de los brazos, las piernas, los muslos e incluso en el espacio interciliar. Estas lesiones cedieron después de dos meses de tratamiento con antihistamínico ordenado crónicamente e hidratación cutánea.
Al presentarse a la consulta, gracias al examen físico solo se evidencia lesión a nivel infraumbilical (figura 1), con características típicas como eritema, edema, vesículas, numerosas pápulas, costras hemáticas, liquenificación por fricción crónica y fisuras.

Figura 1. Fotos tomadas en consultorio de Dra. Yuriet Alexandra Tibaduiza Mogollón. Día de primera consulta

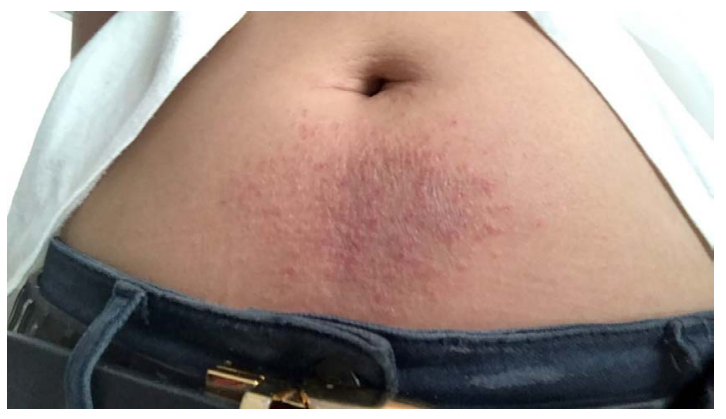

Se diagnostica dermatitis eczematosa alérgica por contacto al níquel y se considera que el evento referido en el 2016 por la paciente corresponde a la presentación poco conocida de "sarna de níquel".

A la paciente se le explica la etiología de su dermatitis, y se indican medidas para evitar contacto con alérgeno y tratamiento con:

1. Clemastina tab $1 \mathrm{mg}$. Tomar 1 tableta cada 12 horas por un mes.

2. Fomentos con solución de Burow (sobres 2,2 gr). Reconstituir y aplicar cada noche por un mes.

3. Agua de vegeto/ agua de Goulard (subacetato de plomo líquido + alcohol $90^{\circ}+$ agua purificada).

4. Pomada con cinc, para usar a diario.

La paciente presentó respuesta eficiente a las medidas instauradas y asistió a consulta para vigilar su progreso, total resolución en 16 días. Fotografía a los cinco días de tratamiento (figura 2) y fotografía a los 13 días de tratamiento (figura 3). A los 16 días por comunicación vía telefónica con la paciente se conoce que las lesiones desaparecieron totalmente. 
Figura 2. Quinto día de tratamiento

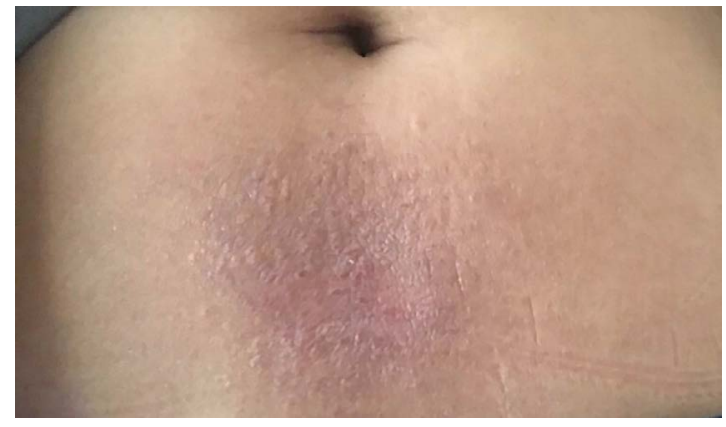

Figura 3. 13 días de tratamiento

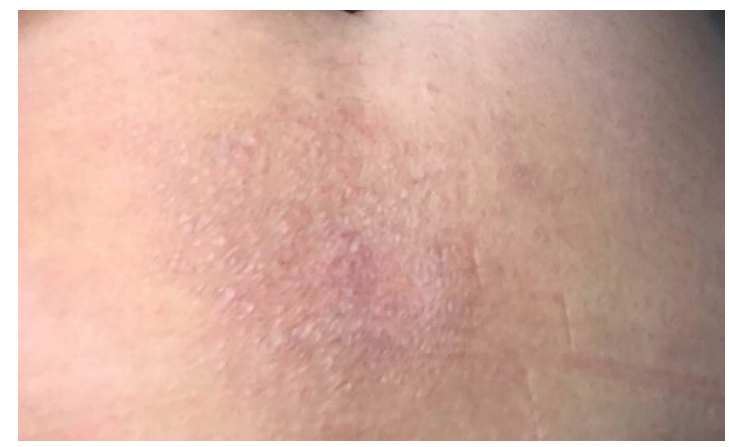

\section{Discusión}

El níquel, por tratarse de un material que proporciona resistencia a la corrosión y aporta tenacidad y resistencia al impacto, cautiva por sus características a la fundición, y representa una excelente alternativa para usar en las aleaciones. Se encuentra en la mayoría de objetos con baño metálico, utensilios de cocina, tijeras, relojes, cremalleras monedas, hebillas de los cinturones, collares, aretes, sujetadores, botones, gafas, oro blanco, prótesis metálicas odontológicas y traumatológicas, pinzas para pelo, pasadores, brazaletes, bolígrafos, dentaduras, placas ortopédicas, tornillos alfileres, instrumentos quirúrgicos, jeringas y coronas dentales.

Teniendo en cuenta que se trata de una exposición crónica por la amplia presencia de níquel en el mercado, es facilitada la sensibilización. Su pequeño tamaño relativo y su capacidad alergénica al entrar en contacto con la epidermis forman complejos hapteno-portadores que al mezclarse con las proteínas de la piel ofrecen las circunstancias imprescindibles para que se originen las dermatitis de contacto.
Una vez se consigue la conjugación, el alérgeno se capta por las células de Langerhans y se transporta a los linfáticos, donde se ejecuta la presentación a los linfocitos $\mathrm{T}$, los cuales liberan linfoquinas y efectivizan la reacción antígeno-linfocito-macrófago. Si el paciente suspende el contacto con el alérgeno los linfocitos pausan su actividad efectora y se constituyen como células memoria, que en empalmes posteriores con el alérgeno crean anticuerpos rápidamente, de ahí la celeridad de la presentación del cuadro clínico en un paciente sensibilizado.

El galeno siempre debe analizar para la categorización diagnóstica la localización de la lesión e indagar sobre los compuestos que podrían estar precipitando el cuadro clínico. Después se pueden practicar "las pruebas de parche" implementadas por Bruno Bloch en 1911. En el caso presentado un parche con sulfato de níquel con vaselina al 5\% fijado durante 48 horas en la espalda de la paciente debía mostrar la reacción típica, siendo de semejantes características a la lesión evidenciada infraumbilical con eritema, vesículas, pápulas e infiltración.

En este caso se usó un método colorimétrico con dimetilglioxima. Este test tiene una sensibilidad de 59,3\% y una especificidad de 97,5\% (4). Con la ayuda de un hisopo impregnado de esta sustancia al friccionarse en la zona de contacto de la hebilla de la correa, al igual que la superficie del botón del pantalón de la paciente, se obtuvo un color pardo rojizo, que indicó presencia de níquel y orientó a la estrategia terapéutica.

Teniendo en cuenta que lo más llamativo en la presentación de caso es lo referido a la dermatitis de contacto señalada como "sarna de níquel", se emprendió una extensa búsqueda en la literatura médica disponible, gracias a la cual se encontró que no hay reportes ni presentaciones de caso previos de sarna al níquel. Asimismo, se desconoce cuándo fue acuñado este término; sin embargo, nos atrevemos a inferir que el término sarna o escabiosis al níquel fue empleado por los galenos que por primera vez se enfrentaron con esta entidad.

Sabiendo que fue hasta 1751 cuando A. F. Cronstedt reconoció el níquel como metal (5) y que en 1873 Jules Garnier declaró un gran depósito de mineral de níquel en Nueva Caledonia con la posterior fundación en 1880 de la Societé Le Nickel, la 
sensibilización en los trabajadores de estas industrias pudo ser la constante y, por tanto, se estableció el diagnóstico de escabiosis al níquel. Esto, al recordar el patrón clínico de eczema numular (6) con gran tendencia a la diseminación a distancia por Sarcoptes scabiei, agente etiológico de la escabiasis o sarcoptosis que corrientemente se maneja por causa del parásito de cuerpo no segmentado, ovoide con cuatro pares de patas.

Por tanto, la llamada sarna de níquel corresponde a las manifestaciones de sensibilización sistémica a este, con talante similar a la reacción causada por Sarcoptes scabiei. Por lo anterior, lo referido por la paciente durante la anamnesis puede encasillarse en esta esta presentación no típica; lastimosamente, no se pudo obtener registro fotográfico para compartir con la comunidad médica.

\section{Recomendaciones generales}

Para evitar la dermatitis o sarna de níquel se recomienda minimizar el contacto de la piel con níquel, usar alternativas como platino, plata, oro acero inoxidable o aluminio en los utensilios del hogar, o elementos con mango de madera o plástico, y en las prendas cubrir con capas de laca de poliuretano (esmalte para uñas). También se aconseja no cocinar con utensilios de níquel, evitar los alimentos enlatados, hongos, frijoles, espárragos, cebollas, maíz, tomates, espinacas, peras, pan integral, chocolate, té y cacao (7).

\section{Agradecimientos}

A mi hermana, Lizeth Tatiana Tibaduiza Mogollón.

\section{Conflictos de interés}

El autor declara no tener de manera directa o indirecta algún tipo de conflicto de intereses financieros, académicos o laborales que puedan poner en riesgo la validez de este estudio.

\section{Referencias}

[1] Dou X, Liu LL. Nickel-elicited Systemic contact dermatitis. Contact Dermatitis. 2003 mar.;48(30):126-9.

[2] Fisher LA, Menné T, Johansen JD. Dose per unit área-a study of elicitacition of nickel allergy. Contact Dermatitis. 2007;56(5):255-261.

[3] Katz SA, Samitz MH. Leaching of Nickel from Stainless Steel consumer commodities. Acta Derm Venerol. 1975;55(2):113-5.

[4] Thyssen JO, Shaje L, Lundgren L, Menné T, Johansen JD, Maibach, H, et al. Sensitivity and specificity of the nickel spot (dimethylglyoxime) test. Contact Dermatitis. 2010 may.;62(2):279-88.

[5] Hernández Polanco F. De los orígenes de la metalurgia a la industria del ferroníquel. 1. ${ }^{\mathrm{a}}$ ed. Bogotá: Edición del Autor; 2007. 320, p.

[6] Aranda G. Tratamiento de las infestaciones cutáneas. FMC. 1996;3(9):608-13.

[7] Arenas R. Dermatosis reaccionales. En: Bernal M, editor. Dermatología. Atlas, diagnóstico y tratamiento. 5 . $^{\mathrm{a}}$ ed. Ciudad de México: McGraw-Hill Interamericana; 2013. p. 47-52. 